\title{
Porphyria Cutanea Tarda Masquerading as Systemic Sclerosis: Two Cases Demonstrating an Important Clinical Observation
}

Elizabeth Tkachenko (D), MD, Department of Internal Medicine, Brigham \& Women's Hospital, Boston, Massachusetts; Joseph C. Pierson, MD, Department of Dermatology, University of Vermont Medical Center, Burlington, Vermont; Ruth Ann Vleugels, MD, MPH, Department of Dermatology, Brigham and Women's Hospital, Harvard Medical School, Boston, Massachusetts, USA. J.C. Pierson and R.A. Vleugels are co-senior authors. Address correspondence to Dr. R.A. Vleugels, Director, Autoimmune Skin Disease Program, Director, Dermatology-Rheumatology Fellowship Program, Vice-Chair, Brigham \& Women's Hospital Department of Dermatology, Harvard Medical School, 221 Longwood Ave., Boston, MA 02115, USA.

Email: rvleugels@bwh.harvard.edu. This study was exempt by the Partners Institutional Review Board and written patient consent was obtained for publication of identifiable photographs.

Porphyria cutanea tarda (PCT) is a heme biosynthesis disorder characterized by photosensitive bullae and skin fragility ${ }^{1}$. Sclerodermoid changes and dystrophic calcification are uncommon, occurring in $18 \%$ and $8 \%$ of patients, respectively ${ }^{1}$. Scarring alopecia in PCT, or alopecia porphyrinica, is rarely described, with 5 reports to date $e^{2,3,4,5,6,7}$.

A 75 -year-old man with longstanding facial and scalp tightening and scalp biopsy demonstrating cutaneous sclerosis over-

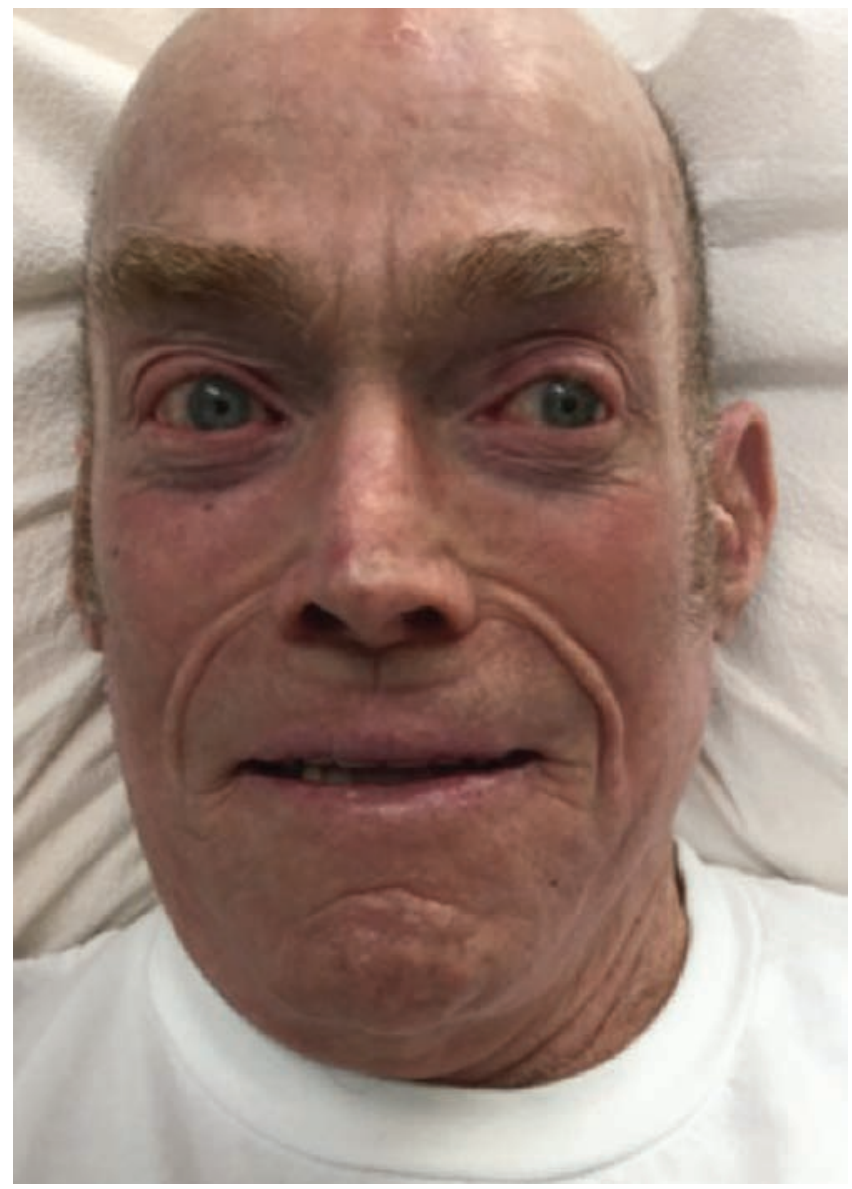

Figure 1. A man in his 70 s with facial and scalp sclerosis as well as prominent ectropion as presenting signs of porphyria cutanea tarda. lying dystrophic calcification was previously diagnosed with systemic sclerosis (SSc). Antinuclear antibody was positive (1:1280), while anticentromere, Scl-70, and RNA-polymerase-III were negative. Examination revealed facial and scalp sclerosis with ectropion (Figure 1) and 2 scalp ulcers with rock-hard calcinotic nodules. There was no edema or sclerosis of the hands/feet, or nailfold changes. He denied Raynaud phenomenon (RP). PCT was suspected and 24-h urine porphyrins revealed uroporphyrin $427 \mathrm{nmol} / 24 \mathrm{~h}$ (normal < 30), confirming this diagnosis.

An 80-year-old female with a history of SSc was referred for alopecia, with scalp biopsy resembling morphea or SSc.

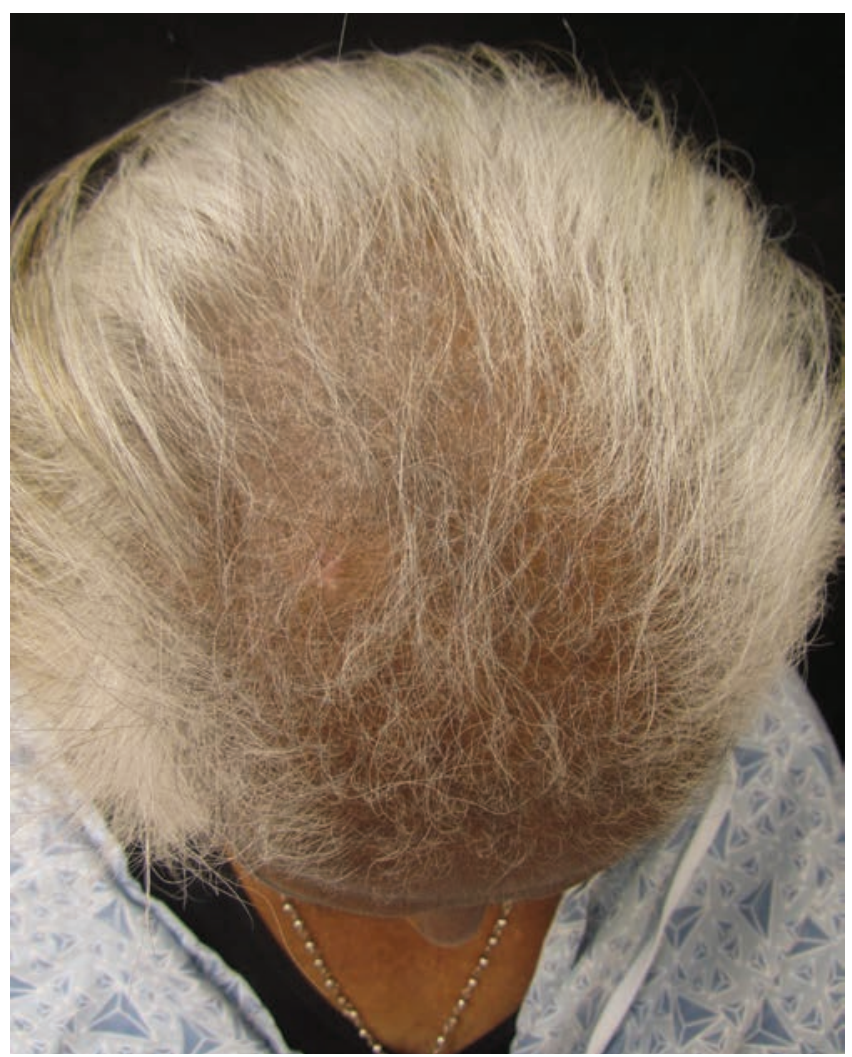

Figure 2. A woman in her 80 s with scarring alopecia of the vertex scalp as a presenting sign of porphyria cutanea tarda. 
She reported progressive hyperpigmentation, denying photosensitivity, blistering, extremity swelling/tightening, and RP. Examination revealed scarring alopecia (Figure 2), malar hypertrichosis, and hyperpigmentation of the face, trunk, and extremities. Elevated urine $(879.5 \mathrm{mcg} / 24 \mathrm{~h}$; normal $<22)$ and plasma $(24.9 \mathrm{mcg} / \mathrm{dl}$; normal < 1) uroporphyrins confirmed PCT.

Atypical sclerodermatous features, including alopecia porphyrinica, may suggest PCT, even in the absence of photosensitivity or blistering. To our knowledge, our cases are the first ones reported masquerading as SSc; PCT must be considered in the differential diagnosis of sclerotic skin disease. Because biopsy does not distinguish PCT from SSc and morphea, investigation with porphyrin levels is imperative for diagnosis.

\section{REFERENCES}

1. Grossman ME, Bickers DR, Poh-Fitzpatrick MB, Deleo VA, Harber LC. Porphyria cutanea tarda. Clinical features and laboratory findings in 40 patients. Am J Med 1979;67:277-86.
2. Volksbeck SI, Nashan D, Bruckner-Tuderman L, Braun-Falco M. Localized sclerosis of the scalp (alopecia porphyrinica) as predominant presentation of porphyria cutanea tarda. J Eur Acad Dermatol Venereol 2007;21:1125-7.

3. Khayat R, Dupuy A, Pansé I, Bagot M, Cordoliani F. [Sclerodermatous changes in porphyria cutanea tarda: Six cases]. [Article in French] Ann Dermatol Venereol 2013;140:589-97.

4. Inglese MJ, Bergamo BM. Large, nonhealing scalp ulcer associated with scarring alopecia and sclerodermatous change in a patient with porphyria cutanea tarda. Cutis 2005;76:329-33.

5. Thomas CL, Badminton MN, Rendall JR, Anstey AV. Sclerodermatous changes of face, neck and scalp associated with familial porphyria cutanea tarda. Clin Exp Dermatol 2008;33:422-4.

6. Campos S, Lencastre A. Quiz your knowledge: Expanding scarring alopecia in a patient with porphyria cutanea tarda. Eur J Dermatol 2017;27:222-3.

7. MacGillivray ME, Salopek TG. Porphyria cutanea tarda presenting with scleroderma, ichthyosis, alopecia, and vitiligo. Case Rep Dermatol 2018;10:115-21. 